\title{
O Sistema Nacional de Pesquisa Agropecuária e a Análise dos Investimentos no Fundo Setorial do Agronegócio
}

\author{
National System of Agricultural Research and the Analysis of Investments \\ in the Agribusiness Sectorial Fund \\ Caroline Nascimento Pereira ${ }^{1,2}$ (1), Cesar Nunes de Castro ${ }^{3,4}$ (1) \\ ${ }^{1}$ Universidade Estadual de Campinas (UNICAMP), Campinas (SP), Brasil. E-mail: carolinenasper@gmail.com \\ ${ }^{2}$ Programa de Pesquisa para o Desenvolvimento Nacional (PNPD), Diretoria de Estudos e Políticas Regionais, Urbanas e \\ Ambientais (DIRUR), Instituto de Pesquisa Econômica Aplicada (IPEA), Brasília (DF), Brasil. \\ ${ }^{3}$ Universidade de Brasília (UNB), Brasília (DF), Brasil. E-mail: cesar.castro@gmail.com \\ ${ }^{4}$ Diretoria de Estudos e Políticas Regionais, Urbanas e Ambientais (DIRUR), Instituto de Pesquisa Econômica Aplicada (IPEA), \\ Brasília (DF), Brasil.
}

Como citar: Pereira, C. N., \& Castro, C. N. (2020). O Sistema Nacional de Pesquisa Agropecuária e a Análise dos Investimentos no Fundo Setorial do Agronegócio. Revista de Economia e Sociologia Rural, 58(2), e181041. https://doi.org/10.1590/1806-9479.2020.181041

\begin{abstract}
Resumo: O artigo realiza a análise do histórico, da estrutura e do financiamento do Sistema Nacional de Pesquisa Agropecuária (SNPA) brasileiro, enfatizando os valores do Fundo Setorial do Agronegócio (CT-Agronegócio), que é destinado ao fomento das atividades de pesquisa e desenvolvimento (P\&D) agrícolas. Analisa-se a evolução do sistema, desde seus primórdios no século XIX até os dias atuais, com a incorporação da inovação e a criação do Sistema de Inovação Agrícola (SIA), que também considera a diversidade de agentes que atuam em redes, com capacidade de interferência no processo de inovação e pesquisa. Para o sucesso do SNPA, verificado com safras recordes de grãos ano após ano, há uma sólida estrutura de financiamento, fundamentado tanto no setor privado como no setor público, em que este último enfatizou a pesquisa básica e aplicada, realizada via Empresa Brasileira de Pesquisa Agropecuária (Embrapa) e pelos fundos setoriais. Entretanto, como o artigo mostra, a participação dos fundos setoriais ainda é considerada pouco expressiva diante do dinamismo do setor agropecuário, porém é importante para a sinalização de mercado da atuação do governo em P\&D do setor agrícola.
\end{abstract}

Palavras-chave: políticas públicas, pesquisa e desenvolvimento, agricultura.

\begin{abstract}
This article analyzes the history, structure and financing of the National Agricultural Research System (SNPA), emphasizing the values of CT-Agronegócio, the sectoral fund focused on the promotion of agricultural R\&D activities. The evolution of the system, from its beginnings in the nineteenth century up to the present, is analyzed with the incorporation of innovation and the creation of the Agricultural Innovation System (SIA), which also considers the diversity of agents that works together in the process of innovation and research. The SNPA achieved good results based on a strong financing structure, including the private and the public sectors, where the latter emphasized applied research conducted through Embrapa and the Funds Sectorial. However, the participation of the Sectoral Funds is still considered not very expressive in the face of the dynamism of the agricultural sector, but important for the market signaling of the government's performance in agricultural R\&D.
\end{abstract}

Keywords: public policy, research and development, agriculture.

\section{Introdução}

A ocupação do território nacional, em grande medida, foi consequência da expansão da área ocupada por diferentes atividades agropecuárias. Essa importância do setor agropecuário no desenvolvimento da economia brasileira se configurou a partir de algumas 
características favoráveis, por exemplo, a extensão do território, e algumas desvantagens, tais como a qualidade dos solos brasileiros, os quais, em sua maioria, apresentavam baixa fertilidade natural. Com base nessas características, a empresa agropecuária que aqui floresceu foi pautada na ocupação de enormes extensões de terra e na baixa produtividade dos cultivos.

Essa formatação permaneceu relativamente inalterada até fins do século XIX, quando, com a rentabilidade auferida pela produção cafeeira, teve início um processo de busca pelo aumento da produtividade agrícola dessa espécie. Data desse período a criação do Instituto Agronômico de Campinas (IAC), fundado em 1887 por Dom Pedro II com o objetivo primeiro de assistir tecnicamente o desenvolvimento da cafeicultura nacional. A partir da criação do IAC, a agricultura brasileira passou a se desenvolver, gradativamente, sob um novo paradigma, o qual defendia que o aumento da produção não dependia exclusivamente da expansão da área de cultivo, mas também do aumento da produtividade. Esse novo paradigma demoraria ainda para se consolidar no setor agropecuário, mas, no decorrer do século $X X$, inexoravelmente, fez-se presente nos debates sobre os rumos da agropecuária brasileira e tornou-se predominante a partir da década de 1970, com a expansão da soja pelo Centro-Oeste brasileiro.

Esse paradigma é pautado pelo binômio "ciência \& tecnologia" (C\&T) e difusão tecnológica. O elemento C\&T é representado pela pesquisa agropecuária que objetiva gerar novas técnicas e tecnologias que permitam o aumento da produtividade dos cultivos agrícolas e da criação animal, enquanto o elemento difusão tecnológica é representado pelo serviço de assistência técnica e extensão rural (Ater), responsável por transmitir os conhecimentos gerados pela pesquisa agropecuária para o conjunto de agricultores. O financiamento dessas atividades foi, à época de sua consolidação no Brasil, décadas de 1950 até 1970, realizado por recursos públicos. Entretanto, a partir da crise fiscal, iniciada em fins dos anos 1970, todo o aparato institucional erigido de C\&T foi pressionado por um cenário de restrição orçamentária.

Deste modo, o objetivo deste trabalho é analisar os recursos arrecadados e empenhados pelo Fundo Setorial do Agronegócio (CT-Agronegócio), o qual, a partir da arrecadação de 17,5\% da Contribuição de Intervenção no Domínio Econômico (Cide), tem como finalidade fomentar a pesquisa e inovação no setor agrícola. Para tal, será realizada a análise do histórico e da estrutura do Sistema Nacional de Pesquisa Agropecuária (SNPA) na próxima seção, seguida da análise do financiamento público da pesquisa agrícola brasileira, por meio da Empresa Brasileira de Pesquisa Agropecuária (Embrapa) e do CT-Agronegócio.

\section{Estrutura do Sistema Nacional de Pesquisa Agropecuária (SNPA)}

O SNPA e até mesmo o Sistema de Inovação Agrícola (SIA) atual possuem suas raízes no século XIX, quando, em 1887, foi criado o Instituto Agronômico de Campinas (IAC). De acordo com Hayami \& Ruttan (1988), o modelo brasileiro de pesquisa agrícola pública se espelhou na experiência alemã de estruturação, no qual competia ao Estado o financiamento dessa atividade, incluindo a edificação de prédios, a instalação de laboratórios e, acima de tudo, a formação de equipes docentes competentes e do mais alto nível nas universidades.

Até as primeiras décadas do século XX, a pesquisa agrícola no Brasil resumia-se à seleção de melhores variedades em termos de produtividades e algumas práticas agrícolas mais simples. O Estado brasileiro, anteriormente dominado por uma elite agrária, passou, a partir dos anos 1930, a ser dominado por uma crescente elite burguesa promotora do desenvolvimento industrial brasileiro. O setor agrícola do país e, consequentemente, a pesquisa agropecuária pública teriam de se adaptar a essa nova configuração. No decorrer desse processo, o papel da agricultura passou a ser o de aumentar a oferta de alimentos (para alimentar uma crescente população urbana) e o de obter divisas via aumento de exportações agrícolas para ajudar a financiar os novos empreendimentos industriais. Com isso, a pesquisa agrícola pública teve de se adaptar às novas políticas governamentais, com ênfase na obtenção de novas cultivares, cada vez mais adaptadas aos solos nacionais e mais produtivas.

Após a instauração do regime militar de 1964, essa ênfase do Estado na modernização e na industrialização do Brasil foi reforçada. A agricultura moderna preconizada pelos 
detentores do poder deveria ser intensiva no uso de capital, e essa visão repercutiu na orientação da pesquisa agropecuária pública. O setor agropecuário deveria utilizar maior quantidade de insumos industriais, notadamente fertilizantes, defensivos químicos, tratores e máquinas agrícolas. Para isso, o Estado financiou a construção de indústrias de fertilizantes no país e criou incentivos para que os agricultores utilizassem esses insumos, por exemplo, por meio do crédito agrícola subsidiado.

O último elo desse novo modelo de agricultura promovido pelo Estado era composto da pesquisa agropecuária, a qual deveria gerar novas técnicas e tecnologias a serem empregadas no novo sistema produtivo de uso intensivo de capital. Foi nesse contexto em que ocorreu a criação da Embrapa em 1973. A esse órgão, caracterizado como empresa pública vinculada ao Ministério da Agricultura, foram delegadas as atribuições de elaborar as políticas de pesquisa agrícola de âmbito nacional desde então. A criação da Embrapa e do Sistema Nacional de Pesquisa Agrícola (SNPA) incentivou, a partir de então, a criação das empresas estaduais de pesquisa em diversos estados. De acordo com Santos \& Ichikawa (1997), as empresas estaduais de pesquisa surgiram nos anos 1970 e, de modo geral, viveram um período de constante crescimento na época do regime militar.

Tal política levou o país à liderança na transferência de tecnologia tropical aos sistemas de produção agropecuária, por meio do modelo ofertista, ou seja, a pesquisa era desenvolvida nos institutos públicos de pesquisa e desenvolvimento (P\&D), difundido pela extensão rural e apropriado pelos agentes (consumidores). Esse modelo teve seu esgotamento nos anos 1990, quando surgiu a necessidade de provocar interação entre os agentes nesse processo. O resultado foi o Sistema de Informação e Agricultura do Conhecimento (Siac), enfocado na conciliação da pesquisa e também na identificação das demandas dos agricultores.

Com o passar dos anos, a trajetória foi evoluindo e chegou nos anos 2000 com a necessidade de considerar o aspecto da inovação, além da variedade de atores envolvidos. A abordagem do Siac foi aprimorada, considerando também a inovação. O resultado desse processo foi o surgimento do SIA, quando se institui formalmente o SNPA em $1992^{1}$ (Mendes et al., 2014). Pelas diretrizes que constam no site da Embrapa, é notável a preocupação do governo em relação ao desenvolvimento e à manutenção do sistema inovativo da área agrícola, fato que surgiu e se consolidou com a constituição do SIA e instituição formal do SNPA (Dossa \& Segatto, 2009).

Entre os objetivos principais do SNPA estão: i) compatibilizar as diretrizes e as estratégias de pesquisa agropecuária com as políticas de desenvolvimento, tanto em nível nacional como regional; ii) assegurar organização e coordenação das matrizes de instituições que atuam no setor; iii) desenvolver um sistema nacional de planejamento para pesquisa, com acompanhamento e avaliação; iv) estabelecer um sistema brasileiro de informação agrícola; v) organizar e racionalizar os meios, métodos e sistemas por meio da informatização das instituições; vi) fomentar a parceria entre as instituições no desenvolvimento de C\&T para a agropecuária; vii) favorecer o intercâmbio de pessoal para capacitação (Embrapa, 2017²).

A trajetória do SNPA pode ser descrita, conforme Canciani et al. (2016), em quatro períodos: de 1972 a 1976, momento de redefinição de um novo modelo de pesquisa agropecuária no Brasil; de 1977 a 1989, período de crise financeira da pesquisa agrícola pública; de 1990 a 2002, continuação do período de ajuste, porém com a instituição formal do SNPA; e, por fim, de 2006 a 2015, retomada dos investimentos com PAC Embrapa. Este trabalho propõe um novo período a ser datado de fins de 2015 até os dias atuais, com a retomada da política de ajuste fiscal, o que resulta(rá) na reformulação e/ou extinção de algumas Organizações Estaduais de Pesquisa Agropecuária (Oepas).

No primeiro período (1972-1976), houve a redefinição de um novo modelo de pesquisa agropecuária no Brasil, sob coordenação do Ministério da Agricultura ${ }^{3}$ e participação dos

\footnotetext{
1 O SNPA foi instituído em 1992 pela Portaria n 193, de 7 de agosto de 1992, do Ministério da Agricultura, autorizado pela Lei Agrícola (Lei $n^{\circ} 8.171$, de 17 de janeiro de 1991) (Embrapa, 2017).

2 De acordo com a Portaria n 193, de 7 de agosto de 1992, do Ministério da Agricultura.

${ }^{3}$ Nesse período, chamava-se Ministério da Agriculta e Reforma Agrária (MARA).
} 
Conselhos (nacional e regional), e a criação da Embrapa no ano seguinte, em 1973, por meio da Lei $n^{\circ}$ 5.851, de 7 de dezembro de 1972. Em 1973, também ocorreu a extinção do Departamento Nacional de Pesquisa Agropecuária (DNPEA) ${ }^{4}$. Nesse período, o Governo Federal incentivou a capacitação maciça de pesquisadores no exterior, principalmente nos Estados Unidos. Ademais, nessa primeira fase, houve a criação da Empresa Brasileira de Assistência Técnica e Extensão Rural (Embrater), em 1974.

Essa fase foi importante para a organização e a coordenação da pesquisa agropecuária no Brasil, principalmente pela criação da Embrapa. Todo o período foi profícuo para o desenvolvimento agrícola, pois havia o apoio do Poder Executivo, articulação com a Embrater e com setor privado, apoio financeiro e convênio com as empresas estaduais de pesquisa. Esses fatos possibilitaram o crescimento da Embrapa, tornando-se uma empresa com estrutura abrangente, articulada com o setor privado e público em todas as esferas, órgãos internos e externos e instituições de pesquisa nacionais e internacionais.

O segundo período (1977-1989) foi marcado pela crise financeira fruto da fuga de capitais do fim dos anos 1970, o que provocou redução dos investimentos em pesquisa pública. A crise fiscal gerou diminuição no repasse de recursos pelo Governo Federal aos estados por intermédio da Embrapa. Como consequência, houve reestruturação dos Institutos Estaduais de Pesquisa, conhecidos como Oepas, com a extinção de algumas unidades como as do Ceará e Maranhão ou o processo de fusão com agências de extensão rural, como Bahia e Espírito Santo. Para enfrentar esse cenário de receitas diminuídas, essas instituições tiveram de reajustar suas linhas de atuação e/ou buscar fontes alternativas de financiamento por meio de convênios com outras instituições públicas e, inclusive, com parceiros da iniciativa privada.

O período seguinte (1990-2002) ficou marcado pelo ajuste fiscal, com medidas para conter os gastos, o que não poupou a área da agricultura, como a extinção da Embrater em 1990. Entretanto, apesar do ajuste, havia interesse em fortalecer a pesquisa agrícola, fato consumado com a autorização para a instituição do SNPA. Em 1992, o país tinha um SNPA formalmente instituído com a coordenação da Embrapa e em convênio com os estados, o Distrito Federal, os territórios, os municípios, as entidades públicas e privadas, as universidades, as cooperativas, os sindicatos, as fundações e as associações. O SNPA também instituiu que a pesquisa agrícola deveria estar integrada à assistência técnica e extensão rural $^{5}$, dar prioridade ao melhoramento dos materiais genéticos e à geração e à adaptação de tecnologias agrícolas destinadas ao desenvolvimento de pequenos agricultores, observando as características regionais.

E o último período (2006-2015) foi marcado pela retomada dos investimentos em pesquisa agrícola, com o lançamento e a execução do Programa de Fortalecimento e Crescimento (PAC) Embrapa ${ }^{6}$. Ademais, também foram elaborados Planos de Gestão Estratégica (PGE) das Oepas e instituída a Agência Nacional de Assistência Técnica e Extensão Rural (Anater). Nessa última etapa, a Embrapa e o Conselho Nacional dos Sistemas Estaduais de Pesquisa Agropecuária (Consepa) ${ }^{7}$ requisitaram ao Centro de Gestão e Estudos Estratégicos (CGEE) (Centro de Gestão e Estudos Estratégicos, 2006) ${ }^{8}$ um levantamento sobre as condições operacionais e potencialidades das Oepas, para uma reestruturação da sua capacidade operacional e também com repasses financeiros. Porém, o final do período não foi tão exitoso quanto o planejado. Embora, em 2014, tenha ocorrido a instituição da Anater para promover, estimular, coordenar e implementar programas para maior integração da assistência técnica e extensão rural, em 2015 ocorreu o fim da Empresa Baiana de Desenvolvimento Agrícola (EBDA), a Oepa do estado da Bahia, que era a fusão

\footnotetext{
${ }^{4}$ DNPEA foi estabelecido em 1971 fruto da política de modernização e expansão agrícola dos anos 1960 (Mendes et al., 2014) ${ }^{5} \mathrm{~A}$ intempestividade dessa proposta de integração entre C\&T e os serviços de difusão de tecnologia no meio rural é flagrante ao se considerar que, à época da criação formal do SNPA (1992), a Embrater havia sido recentemente extinta, e todo o aparato estatal de Ater estava em franco declínio. Até os dias atuais, essa integração não foi realizada em âmbito nacional.

${ }^{6}$ PAC Embrapa ocorreu em 2008 com o objetivo de promover desenvolvimento continuado e sustentável da agricultura brasileira, apoiado em 10 projetos: Amazônia, segurança alimentar, aproveitamento de recursos naturais, produção agrícola sustentável, competitividade e sustentabilidade da agricultura familiar, agroenergia, governança e inovações institucionais, revitalização e modernização da capacidade intelectual e infraestrutura, recuperação da capacidade das Oepas e monitoramento por satélite.

${ }^{7}$ Conselho criado em 1992 para promover interação entre as Oepas (Mendes et al., 2014).

${ }^{8}$ CGEE (2006).
} 
da empresa de Pesquisa Agropecuária da Bahia (Epaba) e a Empresa de Assistência Técnica e Extensão Rural da Bahia (Emater/BA).

Como um adendo a essa periodização, é possível considerar um quinto momento a partir do fim de 2015, em que, por causa do ajuste fiscal vivido no país, ocorreu a extinção da Fundação Estadual de Pesquisa Agropecuária (Fepagro) ${ }^{9}$, instituição de pesquisa agropecuária do Rio Grande do Sul, uma das mais antigas e importantes de pesquisa pública do Brasil, por conta de reestruturação administrativa no estado, que extinguiu outras 10 instituições de pesquisa estadual. Possivelmente, a extinção da EBDA em $2015^{10}$ constitua o marco inicial desse novo período. O encerramento de atividades de Oepas é fato preocupante para o SNPA, pois o sistema se destaca pelo trabalho em rede, envolvendo parcerias e relacionamentos institucionais entre organizações públicas e privadas, além de organizações da sociedade civil. Essa seria a base do SNPA, que já possui papel de destaque, porém, atualmente, está fragilizada (Canciani et al., 2016).

Apesar das fragilidades emergentes, o diferencial do SNPA é sua organização articulada com o território nacional e distribuída por ele. O SNPA é composto de Embrapa, Oepas, universidades e institutos de pesquisa de âmbito federal ou estadual, além de demais organizações públicas e privadas, direta ou indiretamente vinculadas à atividade de pesquisa agropecuária (Bonacelli et al., 2015; Embrapa, 2017). O Quadro 1 apresenta a estrutura do SNPA considerando as Oepas e unidades descentralizadas e os escritórios da Embrapa. Já as unidades de Emater estão na Figura 1. É importante salientar que, com o processo de reformulação das Oepas entre 1977 e 1989, algumas delas foram unificadas com as Ematers de seus respectivos estados. Deste modo, atualmente, há unidades de Emater em todos os estados, entretanto existem apenas 18 Oepas $^{11}$ pelo Brasil, considerando que, em 10 delas, as atividades de pesquisa, assistência técnica e extensão rural são desenvolvidas conjuntamente $^{12}$. Já a Embrapa está presente em quase todo o território nacional, com exceção do Rio Grande do Norte, Espírito Santo e Alagoas.

Quadro 1 - OEPAs, unidades descentralizadas e escritórios da Embrapa

\begin{tabular}{|c|c|c|c|}
\hline UF & Unidades descentralizadas & Escritórios & Oepas \\
\hline \multicolumn{4}{|c|}{ Região Centro-Oeste } \\
\hline \multirow{8}{*}{ DF } & Embrapa Agroenergia & \multirow{8}{*}{ Escritório Brasília } & \multirow{8}{*}{-} \\
\hline & Embrapa Café & & \\
\hline & Embrapa Cerrados & & \\
\hline & Embrapa Hortaliças & & \\
\hline & Embrapa Informação Tecnológica & & \\
\hline & Embrapa Produtos e Mercado & & \\
\hline & Embrapa Quarentena Vegetal & & \\
\hline & $\begin{array}{c}\text { Embrapa Recursos Genéticos e } \\
\text { Biotecnologia }\end{array}$ & & \\
\hline GO & Embrapa Arroz e Feijão & Escritório de Goiânia & Emater \\
\hline \multirow{2}{*}{ MS } & Embrapa Agropecuária Oeste & \multirow{2}{*}{ Escritório de Dourados } & \multirow{2}{*}{ Agraer } \\
\hline & Embrapa Gado de Corte & & \\
\hline
\end{tabular}

\footnotetext{
${ }^{9}$ O governo do Rio Grande do Sul determinou o fechamento de 12 fundações com decreto publicado no Diário Oficial de 17 de janeiro 2017 (Diário Oficial Estado do Rio Grande do Sul - 17/01/2017 - http://www.corag.rs.gov.br/doedia). ${ }^{10}$ A EBDA foi extinta e substituída pela Superintendência Baiana de Assistência Técnica e Extensão Rural (Bahiater), dentro da estrutura da Secretaria de Desenvolvimento Rural (SDR). Essa modificação foi recebida com muitas críticas, pois a estrutura da EBDA foi desmantelada, e a Bahiater passou a ser apontada como um órgão não mais de Ater, mas como uma receptora de demandas e intermediária de soluções com a iniciativa privada.

11 Nesse cálculo para o estado de São Paulo foi considerada apenas a Apta, pois é a coordenadora das atividades de ciência e tecnologia voltadas para o agronegócio, compreendendo as demais instituições existentes no estado como IAC, IB, IEA, IP, ITAL e IZ.

12 Nos estados de Alagoas, Bahia, Maranhão, Pernambuco, Sergipe, Goiás, Mato Grosso e Mato Grosso do Sul, Espírito Santo e Santa Catarina.
} 
Quadro 1 - Continuação...

\begin{tabular}{|c|c|c|c|}
\hline UF & Unidades descentralizadas & Escritórios & Oepas \\
\hline & Embrapa Pantanal & & \\
\hline MT & Embrapa Agrossilvipastoril & Escritório de Rondonópolis & Empaer \\
\hline \multicolumn{4}{|c|}{ Região Nordeste } \\
\hline $\mathrm{AL}$ & - & & Emater \\
\hline BA & Embrapa Mandioca e Fruticultura & & Bahiater \\
\hline \multirow{2}{*}{ CE } & Embrapa Agroindústria Tropical & & \multirow{2}{*}{ - } \\
\hline & Embrapa Caprinos e Ovinos & & \\
\hline MA & Embrapa Cocais & Escritório de Imperatriz & Agerp \\
\hline PB & Embrapa Algodão & $\begin{array}{l}\text { Escritório de Campina } \\
\text { Grande }\end{array}$ & Emepa \\
\hline PE & Embrapa Semiárido & Escritório de Petrolina & IPA \\
\hline $\mathrm{PI}$ & Embrapa Meio Norte & & - \\
\hline RN & - & & Emparn \\
\hline SE & Embrapa Tabuleiros Costeiros & & Emdagro \\
\hline \multicolumn{4}{|c|}{ Região Norte } \\
\hline$A C$ & Embrapa Acre & & - \\
\hline AP & Embrapa Amapá & & - \\
\hline AM & Embrapa Amazônia Ocidental & Escritório da Amazônia & - \\
\hline PA & Embrapa Amazônia Oriental & & - \\
\hline RO & Embrapa Rondônia & & - \\
\hline $\mathrm{RR}$ & Embrapa Roraima & & - \\
\hline TO & Embrapa Pesca e Aquicultura & & Unitins \\
\hline \multicolumn{4}{|c|}{$\begin{array}{ll}\text { Região Sudeste } \\
\end{array}$} \\
\hline ES & - & & Incaper \\
\hline \multirow{2}{*}{$\begin{array}{l}M \\
G\end{array}$} & Embrapa Gado de Leite & Escritório de Sete Lagoas & \multirow[b]{2}{*}{ Epamig } \\
\hline & Embrapa Milho e Sorgo & $\begin{array}{c}\text { Escritório do Triângulo } \\
\text { Mineiro }\end{array}$ & \\
\hline \multirow{3}{*}{$\mathrm{RJ}$} & Embrapa Agrobiologia & & \multirow{3}{*}{ Pesagro } \\
\hline & Embrapa Agroindústria de Alimentos & & \\
\hline & Embrapa Solos & & \\
\hline \multirow{7}{*}{ SP } & Embrapa Gestão Territorial & \multirow{7}{*}{ Escritório de Campinas } & Apta \\
\hline & Embrapa Informática Agropecuária & & IAC \\
\hline & Embrapa Instrumentação & & Inst. Biológico \\
\hline & Embrapa Meio Ambiente & & IEA \\
\hline & Embrapa Monitoramento por Satélite & & Inst. de Pesca \\
\hline & \multirow[t]{2}{*}{ Embrapa Pecuária Sudeste } & & $\begin{array}{c}\text { Inst. de } \\
\text { Zootecnia }\end{array}$ \\
\hline & & & ITAL \\
\hline \multicolumn{4}{|c|}{ Região Sul } \\
\hline \multirow{2}{*}{ PR } & Embrapa Florestas & Escritório de Londrina & lapar \\
\hline & Embrapa Soja & Escritório de Ponta Grossa & \\
\hline SC & Embrapa Suínos e Aves & Escritório de Canoinhas & Epagri \\
\hline \multirow{4}{*}{ RS } & Embrapa Clima Temperado & & \multirow{4}{*}{ Fepagro } \\
\hline & Embrapa Pecuária Sul & Escritório de Capão do Leão & \\
\hline & Embrapa Trigo & Escritório de Passo Fundo & \\
\hline & Embrapa Vinho & & \\
\hline
\end{tabular}




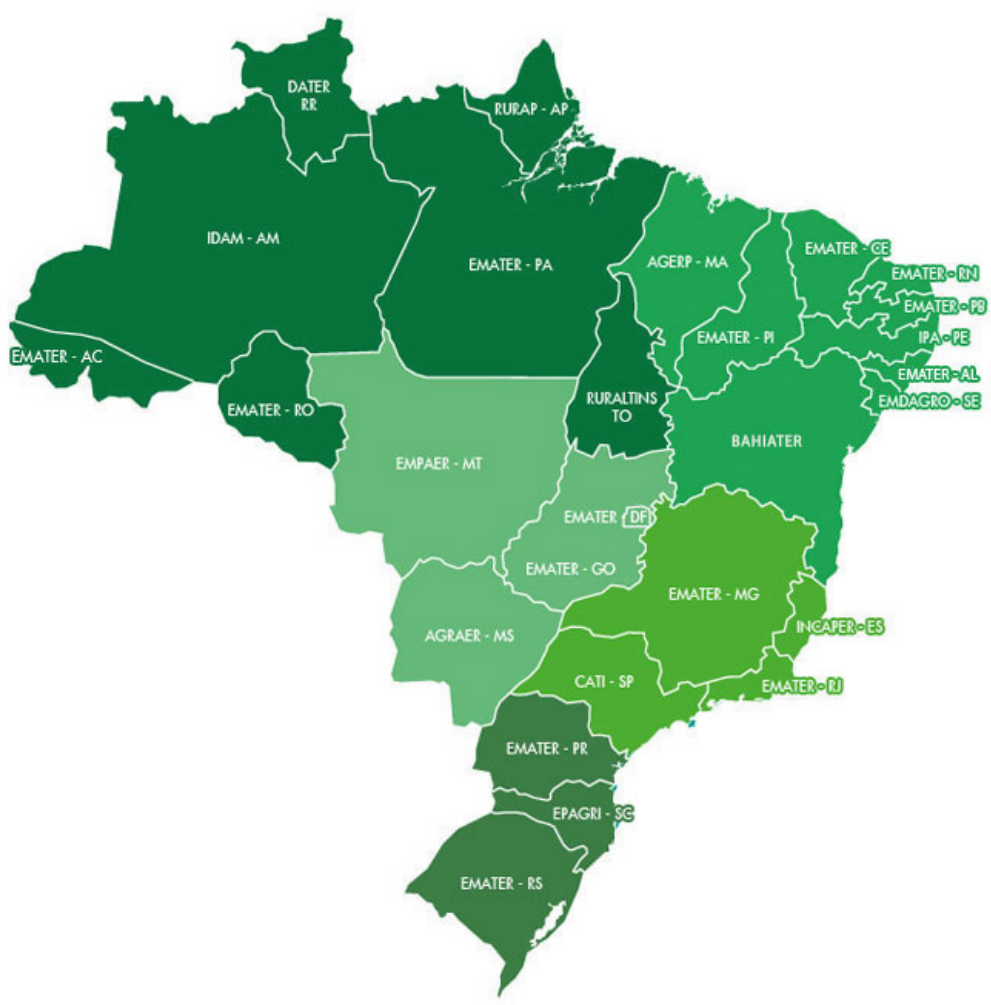

Figura 1 - Assistência técnica e extensão rural (Ater), 2017.

Fonte: Associação Brasileira de Entidades Estaduais de Assistência Técnica e Extensão Rural (2017).

Ainda nos anos 1960, somente o Rio Grande do Sul e Pernambuco ${ }^{13}$ possuíam institutos de pesquisa agronômicos estaduais com alguma significância, além de São Paulo. As Oepas foram surgindo nos anos 1970 e 1980 com o objetivo de observar e atender às demandas dos agricultores e fornecer pesquisa e inovação tecnológica de acordo com as especificidades de cada região e localidade (Mendes et al., 2014).

Entretanto, as Oepas vêm sofrendo uma deterioração em suas atividades, conforme já mencionado sobre a reestruturação ocorrida nos anos 1990 e, mais recentemente, o fim da EBDA (BA) e a extinção da Fepagro (RS). Como as Oepas sobrevivem de repasses realizados via Embrapa e com a centralização dos recursos nos anos 1990 nesta instituição, bem como a necessidade de atuar de forma diversificada para atender às demandas nacionais e locais, as Oepas viram seus recursos minguarem.

É discutível o papel desempenhado pela Embrapa, sendo parceira e concorrente na disputa por recursos com as Oepas, o que leva a uma relação um tanto conflituosa entre as instituições participantes e coloca seu papel de coordenadora em questionamento (Mendes et al., 2014). Os autores afirmam que o SNPA não se consolidou como sistema, pois foi formado por instituições com forte heterogeneidade em todos os aspectos, com a Embrapa assumindo papel protagonista e em competição com as Oepas. Não significa que o SNPA não tenha papel relevante; pelo contrário, é incontestável, mas são inegáveis suas debilidades quanto à articulação e à integração dos institutos públicos de pesquisa.

O protagonismo da Embrapa se explica em grande parte pelo custo elevado da pesquisa tecnológica. Com a sua criação nos anos 1970, a pesquisa nacional e estadual passou a ser centralizada na Embrapa, a qual estimulou a criação das Oepas (Dossa \& Segatto, 2009). Tal importância dessa empresa se deve não apenas ao seu papel no SNPA, mas também por ser uma das maiores instituições públicas de pesquisa (IPP) do mundo.

13 O Instituto Agronômico de Pernambuco foi criado em 1930 (Sicsú et al., 2009). 
O que se observa nas discussões atuais é a busca por uma nova abordagem para o SNPA, dado que o modelo discutido e articulado nos anos 1970 não foi implementado conforme sua concepção e seu objetivo. Segundo Canciani et al. (2016), os problemas na coordenação são por causa da escassez de recursos, pois a falta de repasse para as Oepas causou a desarticulação dentro do sistema. Ademais, a distribuição não simétrica das Oepas e unidades da Embrapa por todos os estados brasileiros não colabora para que o SNPA seja forte, pois, além da assimetria espacial, há a assimetria de poder, em que a Embrapa é coordenadora e competidora dos recursos.

Dessa forma, observa-se a desarticulação do SNPA, uma vez que o sistema se perdeu ao tentar envolver muitos atores, carecendo de maior atenção às Oepas, o que resultou na fragilização de sua atuação, com a Embrapa protagonizando o SNPA e pegando para si a maior parte dos recursos financeiros para as pesquisas. A questão dos recursos é recorrentemente citada no estudo desses autores como uma das principais causas da desagregação do SNPA (Mendes et al., 2015).

Em suma, considerando o quadro atual de ajuste fiscal e diante das dificuldades apresentadas para o conjunto das instituições do SNPA, somado ao crescimento das empresas privadas na pesquisa agropecuária, vê-se que o SNPA está com sua estrutura abalada pelo enxugamento gradativo das Oepas, pela diminuição de recursos e pela redução da participação relativa do público em comparação ao privado. Todos esses pontos corroboram a maior fragilidade do sistema e colocam em dúvida seu futuro e sua capacidade de manter a pesquisa agropecuária brasileira em alto nível. Para apresentar melhor os dispêndios e as receitas da pesquisa agropecuária, a próxima seção analisará alguns dados da Embrapa e do CT-Agronegócio.

\section{Investimento em Pesquisa Agropecuária no Brasil}

A importância da pesquisa agropecuária cresceu nos anos 1970, conforme exposto na seção anterior, quando se implantou o SNPA. Até os anos 1960, os ganhos de produção agrícola eram provenientes majoritariamente da expansão de área, ou seja, do uso do excedente do fator terra (Moreira \& Teixeira, 2014). Como havia a necessidade de aumento da produção nas áreas de fronteira agrícola que apresentavam sinais de esgotamento, viu-se a necessidade de expandir a produtividade, ou seja, a pesquisa agropecuária se fez obrigatória para aumentar o volume produzido em cada hectare.

O SNPA surgiu nos anos 1970 tendo a Embrapa como sua coordenadora, o que significava ser organizadora de todo o sistema e maior receptora dos recursos federais para essa atividade. A Embrapa segue sendo a principal fonte de recursos para as ciências agrárias, financiando a estrutura da pesquisa federal, assim como repassa recursos para as Oepas.

O papel de destaque da Embrapa na pesquisa agropecuária brasileira tem explicação para além dos tempos atuais e limites geográficos. Segundo Alves \& Oliveira (2005), os primórdios da pesquisa agrícola foram fomentados em instituições públicas, pois, antigamente, não era permitido que o lucro de descobertas que dessem origem a tecnologias no campo fosse apropriado pela iniciativa privada, o que favoreceu a criação de instituições de pesquisas públicas e a adoção da trilogia ensino-pesquisa-extensão nas universidades. Ademais, há que se considerar o fato de a pesquisa básica não ser atraente para a iniciativa privada, pois esta não está disposta a assumir riscos inerentes a investimentos incertos ou projetos sem aplicação prática no curto prazo.

Deste modo, o investimento público em pesquisa agropecuária no Brasil se deu, principalmente, via Embrapa e CT-Agronegócio. Em menor medida, também há as Oepas, detalhadas na seção anterior, as quais recebem repasses via Embrapa, e as universidades, que são alimentadas com recursos de agências de fomento como o Conselho Nacional de Desenvolvimento Científico (CNPq) e Financiadora de Estudos e Projetos (Finep), por meio dos fundos setoriais.

Entre as fontes de investimentos em pesquisa no agronegócio, a Embrapa é a maior responsável pelo volume dedicado. O Gráfico 1 apresenta dados da receita operacional líquida da Embrapa entre 1999 e 2015, mostrando que houve um crescimento substancial na receita ao longo dos 15 anos. A receita operacional líquida $(\mathrm{RL})$ refere-se às receitas com 
vendas e serviços, às receitas operacionais (repasses recebidos, outras receitas operacionais e convênios), aos resultados das receitas menos as despesas orçamentárias e extraorçamentárias, deduzidos os descontos concedidos, os impostos sobre vendas e serviços (ICMS e ISS), as restituições de receita, os ajustes realizados sobre a receita bruta auferida com vendas e serviços, as retificações de receitas federais e ouras deduções da receita (Embrapa, 2017).

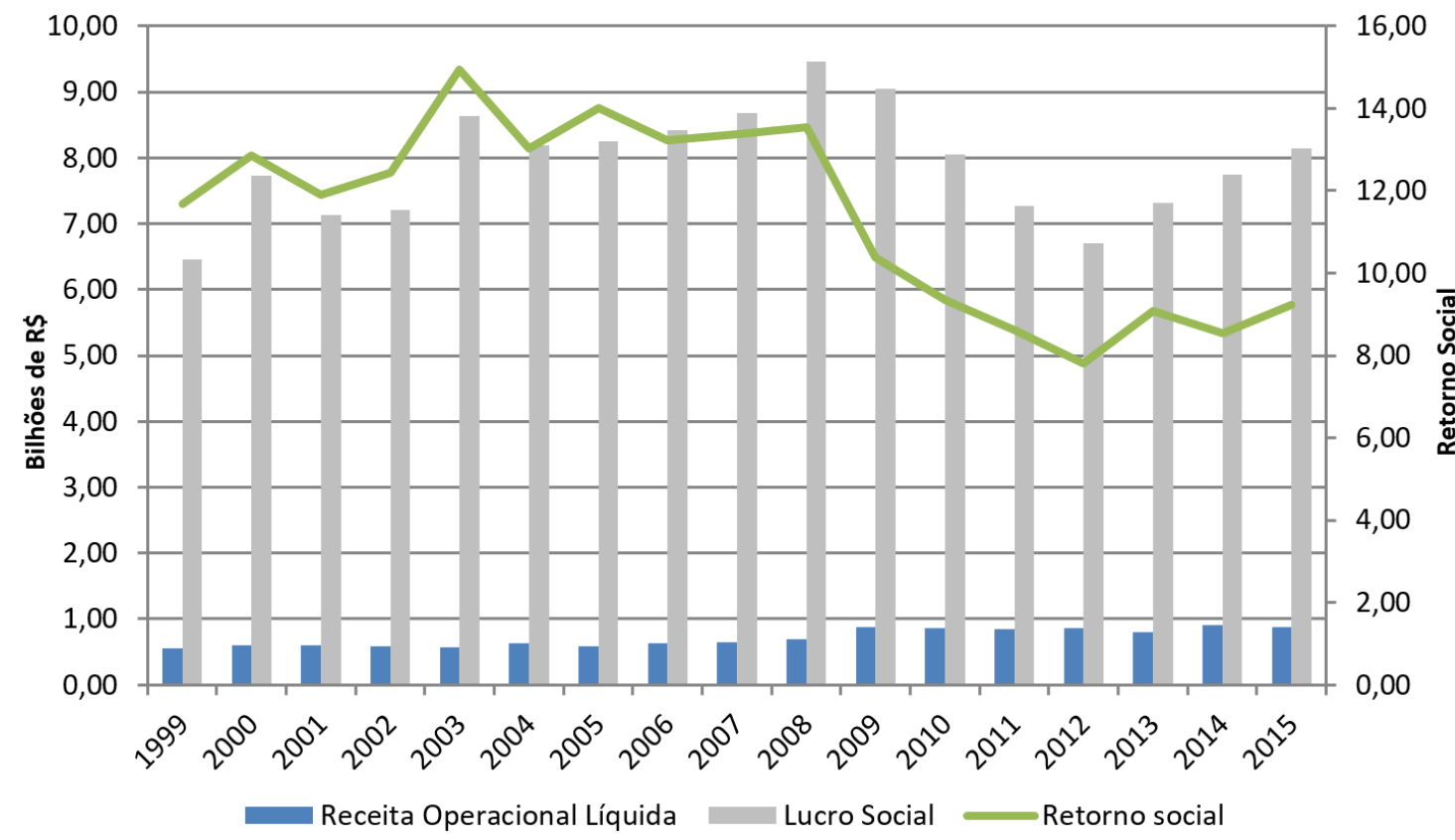

Gráfico 1 - Receita operacional líquida, lucro social ${ }^{14}$ e retorno social ${ }^{15}$ da pesquisa agropecuária da Embrapa, 1999-2015*.

Fonte: elaboração própria a partir dos Balanços Sociais da Embrapa (Embrapa, 2000-2015). *a preços constantes (ano-base $=2000$ ).

Como qualquer dispêndio de recurso público, é natural que se avalie qual o retorno de tal investimento à sociedade. Conforme mencionado na seção anterior, o número de instituições públicas federais (incluindo universidades) e estaduais destinadas à atividade de pesquisa agropecuária é grande. Como forma de justificar esses investimentos, torna-se necessário apresentar para a sociedade quais são os resultados de tais investimentos. Essa necessidade se acentua ainda mais em momentos de crise fiscal, com restrição na disponibilidade financeira do Estado conforme o verificado no decorrer da década de 1980, início de 1990 e novamente desde 2014. Em situações como essa, a eficiência do gasto público se faz ainda mais necessária.

Moreira \& Teixeira (2014) afirmam que, apesar do reduzido número de estudos sobre essa questão, uma relevante fonte para avaliar o retorno dos investimentos públicos em pesquisa agropecuária no caso brasileiro é constituída pelo Balanço Social da Embrapa ${ }^{16}$, publicação anual da empresa. Na edição de 2014, por exemplo, a Embrapa estimou que, para cada $R \$ 1,00$ aplicado em suas atividades de pesquisa agropecuária, foi gerado um retorno de $R \$ 8,53$ à sociedade brasileira. Além disso, o retorno dos investimentos realizados pela Embrapa na geração das 106 tecnologias monitoradas e avaliadas desde 1997, ano de criação

\footnotetext{
${ }^{14}$ Lucro social é o resultado dos benefícios econômicos gerados em função dos lucros líquidos obtidos por aqueles que adotam as tecnologias disponibilizadas pela Embrapa.

${ }^{15}$ Retorno social é a taxa obtida a partir da divisão do lucro social pela receita operacional líquida, ou seja, a relação entre o que a sociedade obteve de benefícios sobre as receitas geradas com vendas e serviços pela Embrapa.

${ }^{16}$ A informação contida no Balanço Social da Embrapa deve ser avaliada com parcimônia, visto que é uma informação produzida pela própria empresa para justificar os investimentos recebidos.
} 
do Balanço Social, também indica alta rentabilidade, com taxa média de retorno (TIR) de 39,4\% (Embrapa, 2014).

Dentro dessa perspectiva, é importante observar o lucro social da Embrapa ${ }^{17}$ (Gráfico 1), em que este representa o impacto econômico de tecnologias desenvolvidas e transferidas para a sociedade. O lucro social da Embrapa, em 2015, foi de $R \$ 8,14$ bilhões (a preços de 2000), ao passo que, em 1999, foi de $R \$ 6,46$ bilhões. Esses valores podem ser melhor analisados por meio da taxa de retorno social - a qual relaciona o lucro social pela receita líquida -, que, em 2015, foi de 9,23, indicando que, nesse ano, houve um retorno à sociedade de 9,23 vezes em relação a cada $\mathrm{R} \$ 1,00$ recebido pela Embrapa (Embrapa, 2015).

A taxa de retorno atingiu seu maior valor em 2003, de 14,94, chegando a 2012 ao seu menor valor, de 7,80. A média da taxa de retorno social no período foi de 11,45, porém, desde o ano de 2010, a taxa vem apresentando leve declínio. Apesar do decréscimo, a taxa de retorno dos investimentos públicos na Embrapa é considerada muito elevada, porém a redução no custeio da pesquisa tem feito esse retorno cair, mesmo havendo capital humano e físico de grande valor (Alves \& Oliveira, 2005).

Com isso, a redução do custeio de pesquisa na Embrapa coloca em discussão o futuro da pesquisa agropecuária pública nacional, pois é difícil, em um país com forte atuação no agronegócio, a pesquisa da iniciativa privada substituir os investimentos públicos, pois, muitas vezes, o investidor privado/empreendedor não quer assumir o risco. Ademais, experiências mostram que pesquisa privada é muito mais produtiva nos países onde o Estado investiu primeiramente nesse tipo de pesquisa.

\subsection{Fundos Setoriais}

Os fundos setoriais surgiram pela necessidade de adequação ao novo modelo de financiamento da inovação que surgiu pós-1990. Até então, o sistema era caracterizado por um modelo ofertista-linear, em que a pesquisa era desenvolvida pelos centros de $P \& D$, disseminada pela extensão rural e apropriada pelos agricultores. O novo modelo procurava agregar todos os agentes existentes, de forma a se tornar um modelo sistêmico, o chamado SIA.

Desta forma, os fundos setoriais foram idealizados como novo instrumento de política científica e tecnológica para o Brasil, fundamentado em modernas teorias de inovação. Tal modelo sistêmico prevê que as áreas de conhecimento e pesquisa são cada vez mais interdependentes e interativas, com diversos atores e múltiplas instituições com papéis e funções diferenciadas (Gomes et al., 2015).

Paralela a essa abordagem, havia também a questão econômica, derivada do ajuste fiscal e da política de privatizações. A abordagem de que os fundos surgiram por causa das privatizações parte da ideia de que eles são fruto da nova política tecnológica nacional, a qual previa aumento da produtividade industrial e da capacidade de desenvolver novas tecnologias (Kubota et al., 2012). Nesse modelo, o Estado, por meio dos fundos setoriais, promoveria o estímulo à produtividade e competitividade de setores selecionados.

Trata-se de visões complementares, pois, nos anos 1990, ganhou importância a abordagem de caráter sistêmico, que leva em consideração a influência simultânea de fatores institucionais, econômicos e organizacionais, originando-se da impossibilidade de se explicar o porquê de haver diferentes níveis de desenvolvimento econômico (redes), assim como havia um novo contexto econômico e industrial que demandava fontes extras de financiamento da inovação e da pesquisa.

Posto isso, os Fundos de Apoio ao Desenvolvimento Científico e Tecnológico (FNDCT), conhecidos como fundos setoriais, foram mecanismos criados nos anos 1990 para estimular o sistema de C\&T nacional. Os recursos derivavam de contribuições incidentes sobre o faturamento de empresas e/ou sobre o resultado da exploração de recursos naturais pertencentes à União, parcela de Imposto sobre Produtos Industrializados (IPI) de certos setores e da Cide incidente sobre os valores que remuneram o uso ou a aquisição de conhecimentos tecnológicos/transferência de tecnologia no exterior (Brasil, 2017).

\footnotetext{
17 Sobre retornos econômicos de tecnologias geradas pela Embrapa, ver Avila et al. (2005) e Avila et al. (2008).
} 
Além de estimular a ciência e tecnologia em diversos setores, os fundos setoriais também foram criados com o objetivo de reduzir as desigualdades regionais, ao assegurar aproximadamente 30\% dos recursos existentes para projetos das regiões Norte, Nordeste e Centro-Oeste (Brasil, 2017). Foram criados 16 fundos setoriais, dirigidos por uma associação de agentes como representantes do então Ministério da Ciência, Tecnologia e Inovação $(\mathrm{MCTI})$, representantes dos ministérios participantes, agências reguladoras, setores acadêmicos e empresariais, CNPq e Finep, chamados de comitês gestores. Tais comitês têm como função definir as diretrizes, as ações e os planos de investimentos dos fundos. Além dos 16 fundos específicos, há também as ações transversais, que são recursos para programas estratégicos do $\mathrm{MCTI}$, que utilizam recursos de diversos fundos setoriais para uma mesma ação.

Os primeiros fundos foram criados no fim dos anos 1990 e início dos anos 2000, a partir da privatização de alguns setores econômicos, por exemplo, exploração de petróleo, telecomunicações, energia elétrica, transportes, mineração, entre outros, visando aumentar a produtividade e a competitividade ${ }^{18}$. O MCTI indicou o CT-Petro como modelo para a generalização do mecanismo de fundos setoriais, como a mola propulsora de P\&D, com maior articulação com o setor empresarial, incentivo a políticas industriais e oferecimento de soluções científicas e tecnológicas.

Assim, os fundos setoriais, por meio do financiamento de projetos, incentivaram o estabelecimento de rotinas de P\&D nas empresas por meio de parcerias com universidades e institutos de pesquisa, e até mesmo com outras empresas, criando redes de interação entre os agentes produtivos (Kubota et al., 2012). Essas parcerias ressaltam o caráter focal dos fundos, ao buscar o maior comprometimento do setor privado, com foco na empresa e no ambiente favorável às parcerias, além de também ter caráter difuso, com fortalecimento das atividades de Ciência, Tecnologia e Inovação com ênfase no apoio às inovações nos setores selecionados e desconcentração regional/cooperação (Gomes et al., 2015).

Para tal funcionamento, os fundos possuem como características básicas: a) vinculação de receitas, em que os recursos não podem ser transferidos entre os fundos; b) plurianualidade, que se refere ao apoio a ações e projetos com duração superior a um exercício fiscal; c) gestão compartilhada entre representantes do MCTI, agências reguladoras, comunidade científica e setor empresarial; d) fontes diversas, com recursos oriundos de setores produtivos variados, derivados de receitas como royalties, compensação financeira, licenças, autorizações etc.

Já o funcionamento dos fundos ocorre de forma direta, com os recursos canalizados para o FNDCT e administrado pela Finep, sob responsabilidade do MCTI. Já o CNPq e a Finep são agências encarregadas de administrar os recursos de acordo com diversas modalidades. Para a implementação das ações, o FNDCT se vale de três mecanismos: a) edital público (chamada pública), para apresentar projetos para áreas temáticas definidas; b) carta-convite, a partir de uma demanda o fundo convida instituições para apresentar propostas para gerar produtos e processos; c) encomenda, que diz respeito a casos específicos e de urgência.

Por fim, o destino dos recursos segue para: fundos setoriais, subvenção econômica, ações transversais e recursos sob supervisão do FNDCT (Brasil, 2017). Institucionalmente, $50 \%$ dos recursos arrecadados pelo fundo devem ser destinados a ações transversais, e 30\%, às regiões Norte, Nordeste e Centro-Oeste. Entretanto, não se observa tal destinação na prática, pois os 30\% não têm sido alcançados para as regiões citadas, especificamente para o Norte, pois há falta de projetos na região (Gomes et al., 2015).

\footnotetext{
${ }^{18}$ O primeiro fundo instituído foi o Fundo Setorial do Petróleo e Gás Natural (CT-Petro) em 1999, a partir da instituição do Conselho Nacional de Política Energética e da Agência Nacional do Petróleo (ANP), os quais previam a destinação de parcela dos royalties para programas de pesquisa e desenvolvimento de tecnologias voltadas à indústria do petróleo.
} 
A Tabela 1 apresenta a distribuição dos projetos e valores contratados para cada fundo setorial entre 1997 e 2014. A linha CT-Transversal respondeu por 35\% do número de projetos do período. Já o CT-Agronegócio respondeu por 2.264 projetos no período, ou seja, 5,3\%, com financiamento de 168 milhões $^{19}$ (a preços de 2000).

Tabela 1 - Número de projetos por fundo e ano de contratação, 1997-2014.

\begin{tabular}{|c|c|c|c|c|c|c|c|c|c|c|}
\hline \multicolumn{11}{|c|}{ Número de projetos por fundo $X$ ano de contratação } \\
\hline Fundo & $\begin{array}{c}1997- \\
2006\end{array}$ & 2007 & 2008 & 2009 & 2010 & 2011 & 2012 & 2013 & 2014 & Total \\
\hline AÇÃO TRANSVERSAL & 2 & 38 & 934 & 1.635 & 2.830 & 2.434 & 3.914 & 2.885 & 482 & 15.154 \\
\hline CT-AERONÁUTICO & 47 & 4 & 21 & 96 & 73 & 24 & 18 & 24 & 18 & 325 \\
\hline CT-AGRONEGÓCIO & 754 & 131 & 359 & 379 & 291 & 94 & 134 & 111 & 11 & 2.264 \\
\hline CT-AMAZÔNIA & 132 & 29 & 96 & 27 & 4 & 75 & 54 & 11 & 1 & 429 \\
\hline CT-AQUAVIÁRIO & 44 & 25 & 24 & 79 & 34 & 14 & 31 & 47 & 6 & 304 \\
\hline CT-BIOTECNOLOGIA & 218 & 104 & 122 & 169 & 73 & 11 & 43 & 79 & 3 & 822 \\
\hline CT-ENERGIA & 863 & 32 & 318 & 40 & 235 & 32 & 8 & 83 & 18 & 1.629 \\
\hline CT-ESPACIAL & 6 & 0 & 0 & 0 & 0 & 1 & 15 & 1 & 0 & 23 \\
\hline CT-HIDRO & 929 & 489 & 211 & 342 & 151 & 39 & 158 & 32 & 16 & 2.367 \\
\hline CT-INFO & 409 & 371 & 190 & 129 & 175 & 128 & 25 & 10 & 0 & 1.437 \\
\hline CT-INFRAESTRUTURA & 826 & 173 & 1.296 & 730 & 907 & 82 & 171 & 107 & 34 & 4.326 \\
\hline CT-MINERAL & 195 & 17 & 195 & 14 & 184 & 33 & 2 & 20 & 5 & 665 \\
\hline CT-PETRÓLEO & 1.822 & 104 & 165 & 147 & 222 & 8 & 21 & 212 & 8 & 2.709 \\
\hline CT-SAÚDE & 414 & 2.589 & 812 & 289 & 176 & 127 & 64 & 68 & 13 & 4.552 \\
\hline CT-TELECOMUNICAÇÃO & 1 & 0 & 0 & 0 & 0 & 0 & 0 & 0 & 0 & 1 \\
\hline CT-TRANSPORTE & 9 & 0 & 0 & 0 & 0 & 0 & 0 & 0 & 0 & 9 \\
\hline FNDCT & 1.414 & 107 & 54 & 32 & 51 & 15 & 13 & 11 & 7 & 1.704 \\
\hline VERDE-AMARELO & 216 & 47 & 72 & 9 & 28 & 2 & 0 & 9 & 2 & 385 \\
\hline [N.I.] & 1.457 & 353 & 283 & 303 & 436 & 142 & 194 & 187 & 106 & 3.461 \\
\hline Total & 9.758 & 4.613 & 5.152 & 4.420 & 5.870 & 3.261 & 4.865 & 3.897 & 730 & 42.566 \\
\hline
\end{tabular}

Fonte: Financiadora de Estudos e Projetos (2017) (obs.: situação em 2 de fevereiro de 2017).

\subsection{CT-Agronegócio}

O CT-Agronegócio é o fundo setorial específico desse setor, criado em 2001 com o objetivo de estimular a capacitação científica e tecnológica nas áreas de agronomia, veterinária, biotecnologia, economia e sociologia agrícola, promover a atualização tecnológica da indústria agropecuária e ampliação da competitividade do setor, além de estimular o aumento de investimentos na área de biotecnologia agrícola tropical e de novas tecnologias (Brasil, 2017).

O investimento em P\&D no agronegócio é de fundamental importância para introduzir o progresso técnico nas cadeias produtivas, tornando-as mais competitivas dentro de um ambiente de integração econômica. O foco dos fundos estaria em projetos, redes cooperativas e grandes projetos estruturantes das universidades, centros de pesquisa e centros tecnológicos.

O CT-Agronegócio foi instituído pela Lei $n^{\circ}$ 10.332, de 19 de dezembro de 2001, e regulamentado pelo Decreto $\mathrm{n}^{\circ} 4.157$, de 12 de março de 2012. A origem dos recursos do CT-Agronegócio é $17,5 \%$ da Cide, cuja arrecadação é proveniente da incidência de

${ }^{19}$ Há que se considerar que o CT-Transversal também destina recursos para o agronegócio, assim como para outros setores (Vieira Filho, 2014). 
alíquota de $10 \%$ sobre a remessa de recursos ao exterior para pagamento de assistência técnica, royalties, serviços técnicos especializados ou profissionais. Os executores do CT-Agronegócio são a Finep e o CNPq.

O CT-Agronegócio foi formulado a partir da constituição de um grupo de dirigentes de ministérios com o intuito de definir um programa de estímulo à pesquisa científica e ao desenvolvimento tecnológico para o setor agropecuário, considerando seus instrumentos, mecanismos de gestão e fontes de financiamento (Benedito, 2010). Entre as fontes de arrecadação, consideravam-se novas tributações como a possibilidade de taxar o uso de agrotóxicos, taxar a comercialização de organismos geneticamente modificados, entre outras. A opção pela Cide ${ }^{20}$ ocorreu a partir da busca por uma alternativa de fonte de recursos para o setor do agronegócio. Ao se realizar a revisão dos atos constitutivos da Cide, alterou-se seu poder de abrangência para elevar a arrecadação, a fim de financiar o Programa de Estímulo à Interação Universidade-Empresa para o Apoio à Inovação, também conhecido como Fundo Verde-Amarelo (FVA) ${ }^{21}$ (Benedito, 2010). Tal mudança na estrutura da Cide permitiu aumentar a arrecadação destinada ao FVA e constituir os fundos setoriais (agronegócio, biotecnologia e recursos genéticos, aeronáutico e saúde). Desta maneira, o CT-Agronegócio, assim como os outros fundos citados, tornou-se beneficiário de parcela de recursos coletados em impostos da Cide.

É interessante observar que, diferentemente do CT-Petro e alguns outros fundos, os recursos provenientes para o CT-Agro não são provenientes do próprio setor. Tal observação se faz pertinente porque mostra a importância do agronegócio para o desenvolvimento do país, em que se buscou uma fonte alternativa de recursos para investimento em pesquisa e inovação com a criação o FVA.

A relação entre valor arrecadado e empenhado ${ }^{22}$ pelo fundo CT-Agronegócio em relação ao total dos fundos setoriais é um valor pouco expressivo, mas tem sua importância resguardada no direcionamento de recursos para esse tema (Gráfico 2). Ademais, o percentual empenhado ultrapassa o arrecadado em praticamente todos os anos até 2010, o que significa que, quanto maior o percentual de empenho, menor será o contingenciamento dos recursos, identificando uma dinâmica favorável à liberação dos recursos do CT-Agronegócio em relação aos demais fundos (Vieira Filho, 2014).

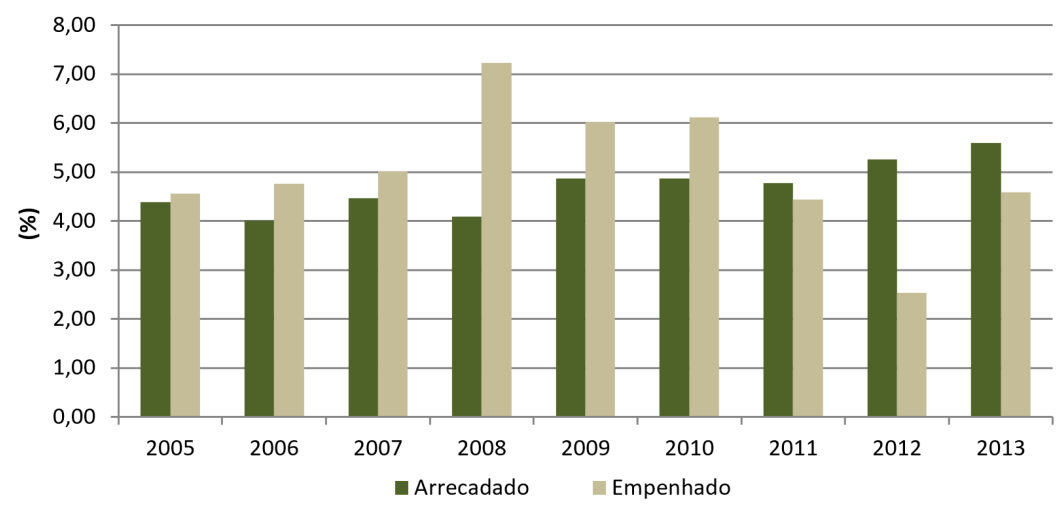

Gráfico 2 - Participação do CT-Agronegócio na arrecadação e no empenho total dos fundos setoriais, Brasil, 2005-2013.

\footnotetext{
${ }^{20}$ A Cide foi instituída pela Lei $n^{\circ} 10.336 / 2001$, com o objetivo de assegurar montante mínimo de recursos para investimentos em infraestrutura de transporte, em projetos ambientais e em subsídios (http://legis.senado.leg.br/legislacao/DetalhaSigen.action?id=552212).

${ }^{21}$ Fundo Verde-Amarelo foi criado com o objetivo de estimular o desenvolvimento tecnológico brasileiro, por meio de programas de pesquisa científica e tecnológica em cooperação entre universidade, centros de pesquisa e setor produtivo (Benedito, 2011).

22 A base de dados utilizada neste artigo é pertencente ao Ministério da Ciência e Tecnologia, o qual se fundamentou em projetos dos Fundos Setoriais/SigFS e Plataforma Lattes do CNPq. A amostra tem como ano-base dezembro de 2015, englobando 42.674 projetos, sendo 33.057 do CNPq (1997 a 2015) e 9.617 projetos da Finep (1999 a 2015).
} 
O CT-Agronegócio apresentou um boom de contratação de projetos, em termos de valor arrecadado, nos anos de 2008 a 2010, quando, em razão da crise financeira global, vivenciou-se uma alta no preço dos alimentos. Tal movimento pode ter provocado maior interesse do setor em investir em P\&D, como se observa no Gráfico 3. Esse movimento também foi constatado para o conjunto dos fundos setoriais, dado que, apesar da crise mundial, o Brasil não foi tão afetado, o que garantiu os investimentos em P\&D na economia. Entretanto, em 2010, já apresentava leve queda, acompanhada de dois anos seguidos de baixa no valor total de contratação de projetos.

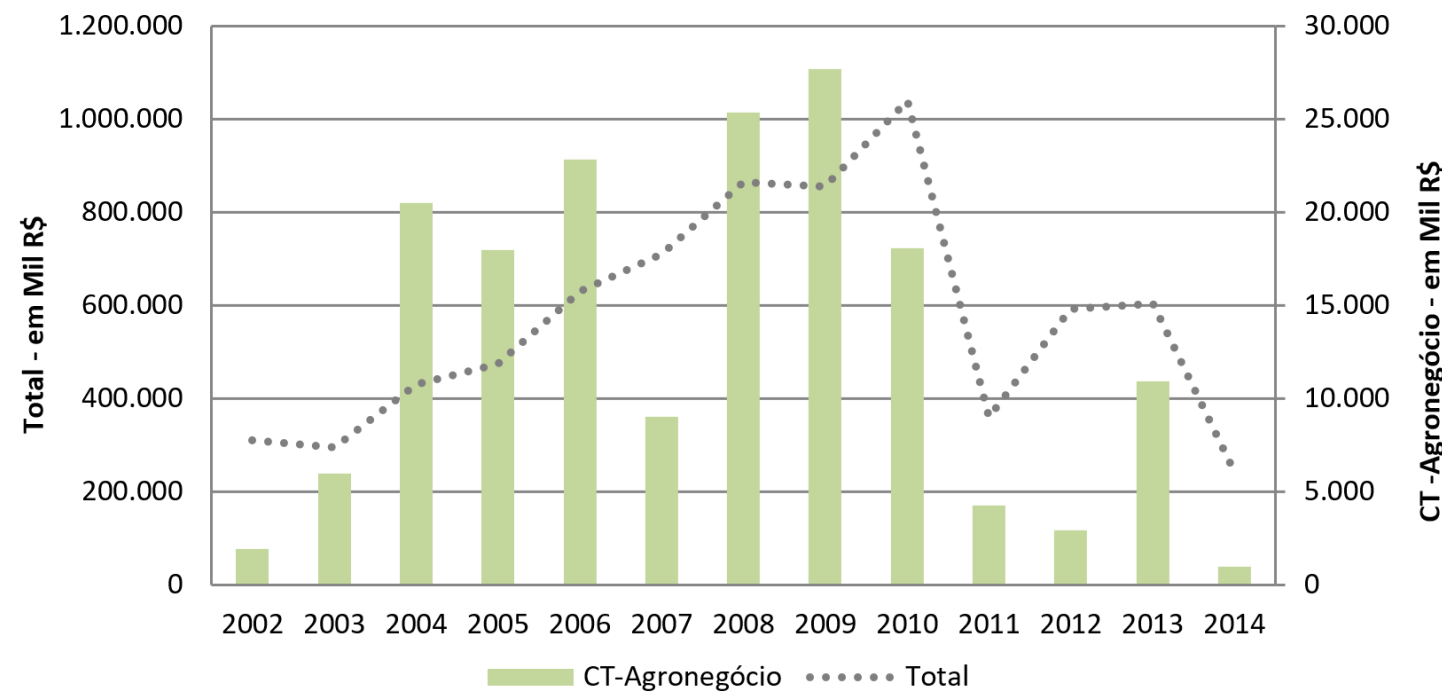

Gráfico 3 - Valor total dos projetos por ano de contratação - total e CT-Agronegócio, 2002-2014. Fonte: elaborado a partir dos dados do Brasil (2017). Valores a preços constantes (ano-base $=2000$ ).

O movimento de investimento em P\&D pode ser guiado por duas motivações. A primeira se dá em momentos de expansão econômica, em que os novos investimentos em pesquisa e tecnologia vão manter a economia aquecida. A segunda se dá em momentos de crise, o que se faz necessário para fortalecer o setor, chamado de política anticíclica, que pode produzir efeitos positivos diante de cenários de desequilíbrio econômico. Vieira Filho (2014) destaca a importância do CT-Agronegócio dentro de um sistema nacional de inovações, o que pode aumentar a produção agrícola. Tal fato foi verificado pós-1970, quando, a partir de considerável investimento na pesquisa agropecuária, o Brasil apresentou ganhos de produtividade (Felema et al., 2013; Ferreira et al., 2016; Gasques \& Conceição, 1997; Fuglie \& Wang, 2012), levando a ser considerado um exemplo de excelência na produção de conhecimento aplicado à produção agropecuária.

Considerando que, entre os anos de 2002 a 2008, o Brasil se beneficiava do boom das commodities, o CT-Agro deveria ter sido uma prioridade de investimento em P\&D, entretanto os números não refletem essa preferência. Além disso, houve forte constrangimento quanto ao seu funcionamento, ao ter um volume de arrecadação maior do que a execução financeira, dado que o fundo não recebe todos os recursos arrecadados pelo Tesouro Nacional, limitando a disponibilidade real de recursos para P\&D na agricultura.

Outro ponto negativo se refere às ações transversais, as quais retiram recursos do fundo setorial e não têm mecanismo claro de real direcionamento de recursos para o CT-Agro (Benedito, 2010). Gomes et al. (2015) demonstram que, apesar da crise de 2008, a arrecadação dos fundos setoriais seguiu ascendente. O Gráfico 4 apresenta a evolução dos recursos arrecadados e empenhados do CT-Agro, permitindo observar crescimento na arrecadação do período. Já o empenho vinha apresentando crescimento, porém, em 2011 e 
2012, o valor foi reduzido, ficando bem abaixo do arrecadado. Tal diferença é apontada como positiva, pois significa uma folga para a utilização dos recursos arrecadados.

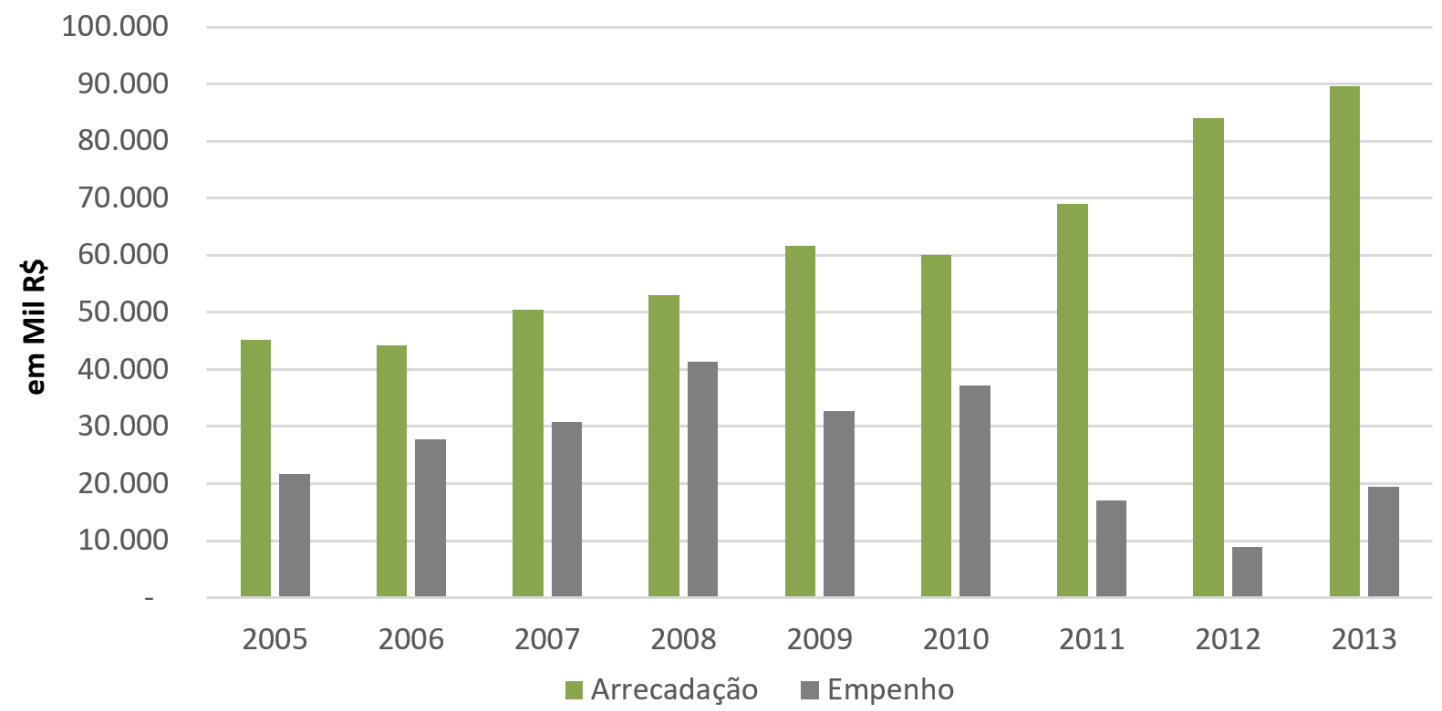

Gráfico 4 - Evolução da arrecadação e do empenho dos recursos do CT-Agronegócio, Brasil, 2005-2013. Fonte: elaborado a partir dos dados do Brasil (2017).

Valores a preços constantes (ano-base $=2000$ ).

Observando os dados acerca do número de projetos e valores contratados por região para o CT-Agronegócio (Tabela 2), tem-se que houve 2.264 projetos, sendo o Sudeste responsável por 36,7\%, enquanto o Norte ficou com 4,9\%. Em termos de valores, o Sudeste ficou com 32,1\%, e o Centro-Oeste, com 30,2\%. A região Norte ficou com apenas 3,4\% do valor total desse fundo. Tais dados mostram que, apesar de o CT-Agro cumprir a regra de destinação de $30 \%$ dos recursos para as regiões Norte, Nordeste e Centro-Oeste, observa-se uma discrepância nos recursos, dos quais o Centro-Oeste absorve grande parte e o Norte recebe relativamente menos do que o número de projetos.

Tabela 2 - Número de projetos e valores contratados por região, CT-Agronegócio, 2000-2015.

\begin{tabular}{ccccc} 
Fundo & $\begin{array}{c}\text { Número de } \\
\text { projetos }\end{array}$ & $\%$ & $\begin{array}{c}\text { Valor contratado } \\
\text { (R\$) }\end{array}$ & $\%$ \\
\hline Centro-Oeste & 386 & 17,0 & 50.814 .798 & $30,2 \%$ \\
Nordeste & 460 & 20,3 & 28.267 .835 & $16,8 \%$ \\
Norte & 112 & 4,9 & 5.720 .871 & $3,4 \%$ \\
Sudeste & 831 & 36,7 & 54.011 .756 & $32,1 \%$ \\
Sul & 475 & 21,0 & 29.445 .661 & $17,5 \%$ \\
[N.I] & 0 & 0,0 & 0 & $0 \%$ \\
Total & 2.264 & 100,0 & 168.260 .921 & 100,0 \\
\hline
\end{tabular}

Fonte: elaborada a partir dos dados do Brasil (2017).

Valores a preços constantes (ano-base $=2000$ ).

Já em termos de número de projetos e valores contratados por tipo de demanda para o CT-Agronegócio, a chamada pública (edital) foi responsável por $91,4 \%$ do total de projetos e $65,4 \%$ do valor total (Tabela 3), ao passo que a encomenda, modalidade de fomento utilizada em caso de demanda específica por parte do governo ou empresas a institutos, universidades ou centros de pesquisa especializados no assunto, ficou responsável por 4,7\% em número de 
projetos e 33,7\% por valor contratado. A carta-convite é uma modalidade ainda mais específica, em que instituições são convidadas a propor projetos para demanda específica.

Tabela 3 - Número de projetos e valores contratados por tipo de demanda, CT-Agronegócio, 2000-2015.

\begin{tabular}{ccccc} 
Tipo de demanda & $\begin{array}{c}\text { Número de } \\
\text { projetos }\end{array}$ & $\%$ & Valor contratado (R\$) & $\%$ \\
Carta-convite & 1 & 0,0 & 302.870 & $0,2 \%$ \\
Chamada pública & 2.069 & 91,4 & 110.025 .816 & $65,4 \%$ \\
Encomenda & 107 & 4,7 & 56.653 .452 & $33,7 \%$ \\
Eventos & 87 & 3,8 & 1.278 .783 & $0,8 \%$ \\
Subvenção & 0 & 0,0 & 0 & $0,0 \%$ \\
[N.I.] & 0 & 0,0 & 0 & $0,0 \%$ \\
Total & 2.264 & 100,0 & 168.260 .921 & \\
\hline
\end{tabular}

Fonte: elaborada a partir dos dados do Brasil (2017).

Valores a preços constantes (ano-base $=2000$ ).

Os dados mostram o CT-Agro como uma porção muito pequena de recursos se comparado com o PIB do agronegócio, com o orçamento da Embrapa ou de universidades tradicionais em pesquisa agropecuária, além dos investimentos de empresas agroindustriais com centro de P\&D atuantes no setor, levando à recorrente discussão de que as fontes de recursos do setor de agronegócio deveriam ser mobilizadas para fortalecimento da pesquisa.

O ponto levantado por Vieira Filho (2014) é que há um déficit de recursos destinados ao CT-Agronegócio em relação ao gasto total do Brasil com o setor agrícola. Entre 2002 e 2008, o valor arrecadado pelo CT-Agronegócio não ultrapassou 1\% do que se gastava com o setor agropecuário. De todo modo, a criação do CT-Agronegócio e seu avanço institucional permitiram a garantia de vinculação de recursos públicos ao fomento de políticas de inovação em ciência e tecnologia ao setor agropecuário, o que permitiu ampliar a fonte de recursos destinados à pesquisa aplicada, complementando os incentivos/gastos realizados no setor. De qualquer forma, em termos relativos, o fundo é pouco expressivo, mas constituiu um passo importante para fomentar a inovação no agronegócio.

\section{Considerações Finais}

A agropecuária brasileira apresentou crescimento vigoroso no volume produzido, tanto pela expansão de área como pela produtividade, desde os anos 1970. Tal incremento na produção e na produtividade se deve aos investimentos em pesquisa e inovação no campo, principalmente por meio de instituições de pesquisa agropecuária pública, como a Embrapa, que foi criada nos anos 1970, e demais instituições de pesquisa pública estaduais, conhecidas como Oepas. Também não se pode desconsiderar a importância do setor privado, porém este somente ganhou força nas últimas décadas após a redução dos recursos para pesquisa pública agrícola.

A pesquisa pública agrícola possui o diferencial de realizar a pesquisa básica e aplicada, as quais não interessam às empresas privadas, pois é um investimento incerto e de alto risco. Entretanto, a sociedade demanda esse tipo de investimento em pesquisa e inovação básicas, para que se alcancem maiores níveis de produção e produtividade, com qualidade, acarretando menor impacto ao meio ambiente. Assim, um problema que surge é de onde virão os recursos para manter a pesquisa sempre em ritmo satisfatório, ainda mais em momentos de ajuste fiscal e de restrição orçamentária.

Um grande desafio para a pesquisa pública agrícola nos dias atuais é obter financiamento, assim como ocorreu no final dos anos 1980 e início dos anos 1990, em que o repasse para a pesquisa agropecuária pública foi diminuído, ameaçando o funcionamento do SNPA. Tal fato foi e novamente torna-se notório com a reestruturação das Oepas, em que algumas se juntaram às Aters e outras até mesmo foram fechadas. 
Para lidar com isso, a pesquisa agropecuária pública brasileira precisa encontrar fontes alternativas de renda, selecionar bem em quais projetos investir os recursos existentes e planejar e administrar o uso desses recursos de forma a evitar ao máximo o desperdício. 0 Estado, em uma tentativa de inovação na forma de financiar o setor, criou, no final dos anos 1990, o modelo de fundos setoriais para financiar investimentos em P\&D em diversos setores da economia, inclusive o agropecuário. A iniciativa é recente, e o montante de recursos para financiamento por essa via ainda é pequeno se comparado aos mecanismos tradicionais (recursos da Embrapa, por exemplo).

Observa-se que há déficit de recursos destinados ao CT-Agronegócio em relação ao montante total de recursos gastos no setor agropecuário, demandando maior atenção para essa via de financiamento, pois, apesar de sua pouca expressividade, é um recurso imprescindível para o setor ao permitir a garantia de vinculação de recursos públicos ao fomento de políticas de inovação em ciência e tecnologia ao setor agropecuário. Além disso, apesar do gradual crescimento desde seu surgimento em 2002, o CT-Agro não recebeu recursos condizentes com o positivo impacto do boom das commodities de 2008 na economia, em proporção aos demais fundos setoriais.

O CT-Agro poderia ser mais bem provisionado e utilizado, não somente pela importância do setor agrícola, mas também pela relevância de realizar investimento público em pesquisa aplicada e básica, que, geralmente, não é feita pelo setor privado. Ademais, possui a capacidade de atrair outras fontes de recursos, complementando os incentivos e gastos realizados no setor.

Deste modo, apesar de, no decorrer da expansão da agropecuária brasileira, empresas privadas terem começado também a investir em pesquisa e geração de tecnologia para o setor, defende-se a continuidade nos investimentos nas instituições de pesquisa agropecuária pública pelos resultados alcançados até o presente, pela capacidade instalada de pesquisa dessas instituições e pela manutenção de linhas de pesquisa que gerem inovação naqueles segmentos menos dinâmicos (boa parte do segmento da agricultura familiar) e com perspectiva reduzida de retorno econômico, os quais, geralmente, não são atrativos para a iniciativa privada.

\section{Referências Bibliográficas}

Alves, E. \& Oliveira, A. J. (2005). O orçamento da Embrapa. Revista de Política Agrícola, 14(4), 73-85.

Avila, A. F. D., Magalhães, M. C., Vedovoto, G. L., Irias, L. J. M., \& Rodrigues, G. S. (2005). Impactos econômicos, sociais e ambientais dos investimentos na Embrapa. Revista de Política Agrícola. 14(4), 86-101.

Avila, A. F. D., Rodrigues, G. S., \& Vedovoto, G. L. (2008). Avaliação dos impactos de tecnologias geradas pela Embrapa. Metodologia de referência. Brasília: Embrapa Informação Tecnológica.

Associação Brasileira de Entidades Estaduais de Assistência Técnica e Extensão Rural - ASBRAER. (2017). Associadas Asbraer. Recuperado em fevereiro de 2017, de https://www.asbraer.org.br/index.php/institucional/associadas

Benedito, J. E. (2010). Fundo Setorial de Agronegócio: caracterização, análise e perspectivas de impactos. (Dissertação de mestrado). Faculdade de Agronomia e Medicina Veterinária. Programa de PósGraduação em Agronegócios, Universidade de Brasília, Brasília.

Bonacelli, M. B. M., Fuck, M. P., \& Castro, A. C. (2015). O Sistema de Inovação Agrícola: Instituições, Competências e Desafios do Contexto Brasileiro. In A. M. Buainain, M. B. M. Bonacelli, C. I. C. Mendes. Propriedade Intelectual e Inovações na Agricultura (Cap. 3, pp. 89-110). Rio de Janeiro: CNPq FAPERJ, INCT/PPED.

Brasil. Ministério da Ciência Tecnologia e Inovação - MCTI (2017). O que são fundos setoriais: MCTI. Brasília Recuperado em 15 de janeiro 2017, de http://www.mct.gov.br/index.php/content/view/28023/A_Missao_dos_Fundos_Setoriais_de_C_T.ht $\mathrm{ml}$.

Canciani, A., Cury, C., \& Carvalho, L. N. (2016). O Sistema Nacional de Pesquisa Agropecuária: Proposta de Implementação para um Novo Modelo de Gestão e Governança (Dissertação de mestrado). Fundação Getúlio Vargas, Escola de Administração de Empresas de São Paulo, São Paulo. 
Centro de Gestão e Estudos Estratégicos - CGEE. (2006). Papel das Instituições Estaduais de Pesquisa Agropecuária Integrantes do Sistema Nacional de Pesquisa Agropecuária. Relatório Regional do Sul. Consolidação dos Relatórios Estaduais Paraná, Santa Catarina e Rio Grande do Sul. Brasília: CGEE.

Dossa, A. A., \& Segatto, A. P. (2009, julho 26-30). Inovação, cooperação interinstitucional em P\&D e o Sistema Nacional de Pesquisa Agropecuária: algumas propostas de pesquisas futuras. In $47^{\circ}$ Congresso da Sociedade Brasileira de Economia, Administração e Sociologia Rural. Porto Alegre.

EMBRAPA. (2014). Balanço Social. Brasília, DF: Embrapa, Secretaria de Comunicação. Recuperado em fevereiro de 2017, de http://bs.sede.embrapa.br/2014/balancosocialembrapa2014.pdf.

EMBRAPA. (2015). Balanço Social. Brasília, DF: Embrapa, Secretaria de Comunicação. Recuperado em fevereiro de 2017, de https://bs.sede.embrapa.br/2015/balancosocialembrapa2015.pdf.

EMBRAPA. (2017) Sistema Nacional de Pesquisa Agropecuária. Recuperado em fevereiro de 2017, de https://www.embrapa.br/snpa

Felema, J., Raiher, A. P., \& Ferreira, C. R. (2013). Agropecuária brasileira: desempenho regional e determinantes de produtividade. Revista de Economia e Sociologia Rural, 51(3), 555-574.

Ferreira, C. B., Araujo, J. A., Tabosa, F. J. S. \& Lima, J. R. F. (2016). Produtividade agrícola nos países da américa latina. Revista de Economia e Sociologia Rural, 54(3), 437-458.

Financiadora de Estudos e Projetos - FINEP. (2017). O que são Fundos Setoriais? from: http://www.finep.gov.br/a-finep-externo/fontes-de-recurso/fundos-setoriais/o-que-sao-fundossetoriais. Recuperado em janeiro de 2017.

Fuglie, K., Wang, S. L. (2012). Productivity growth in global Agriculture shifting to developing countries. Choices. 27(4), 1-7.

Gasques, J. G., \& Conceição, J. C. (1997). Crescimento e produtividade da agricultura brasileira (26 p.). Brasília: Ipea. (Texto para Discussão, n. 502).

Gomes, V. C., Oliveira, L. G., Machado, S. H. S., \& Sousa, L. C. (2015). Os fundos setoriais e a redefiniçao do modelo de promoção de ciência, tecnologia e inovação no Brasil: uma análise à luz do CT-Agro. Revista de Administração, 50(3), 353-368.

Hayami, Y., \& Ruttan, V. (1988). Desenvolvimento agrícola: teoria e experiências internacionais (367р.). Brasília, DF: Embrapa.

Kubota, L., Nogueira, M., \& Milani, D. (2012). Avaliação dos Fundos Setoriais: CT-Info (Texto para Discussão, 1752). Brasília: IPEA.

Mendes, C., Buainain, A. M., \& Fasiaben, M. C. (2014, julho 27-30). O Sistema Nacional de Pesquisa Agropecuária e a Cooperação entre as Instituições Públicas de Pesquisa. In Anais do $52^{\circ}$ Congresso da Sociedade Brasileira de Economia, Administração e Sociologia Rural. Goiânia.

Mendes, C., Buainain, A. M., \& Fasiaben, M. C. (2015). Transferência de Tecnologias Geradas pela Embrapa: Condicionantes Exógenos. In Buainain, A. M., Bonacelli, M. B. M., \& Mendes, C. I. C. Propriedade Intelectual e Inovações na Agricultura (Cap. 5, p. 165-183). Brasília, Rio de Janeiro: CNPq, FAPERJ, INCT/PPED.

Moreira, G. C., \& Teixeira, E. C. (2014). Política pública de pesquisa agropecuária no Brasil. Revista de Política Agrícola, 23(3), 5-14.

Santos, L. W., \& Ichikawa, E. Y. (1997). Organização para a inovação: estratégias de uma empresa de pesquisa do setor agrícola. In J. L. Solleiro, \& R. Falloh, Memorias del VII Seminario Latinoamericano de Gestión Tecnológica - ALTEC (vol. 1, p. 779-800). México: UNAM.

Sicsú, A. B., Dias, A. B., Wanderley, M. B., Silveira, S. K., \& Velho, S. (2009). A Pesquisa Agropecuária nas Organizações Estaduais - OEPAS: diagnóstico e ação. Parceria Estratégica. 14(28), 7-32.

Vieira Filho, J. E. (2014). Políticas públicas de inovação no setor agropecuário: uma avaliação dos fundos setoriais. Revista Brasileira de Inovação, 13(1), 109-132.

Submetido: 5/Jun/2017

Aceito: 21/Abr/2019

JEL Q160; Q140; O30. 